\title{
Obstetric outcome in elderly nulliparous women: a comparative study
}

\author{
Sajeethakumari Raveendran*, Swarnalatha Mohanapu, Yogashalaini Murugaiah
}

Department of Obstetrics and Gynecology, S.R.M. Medical College Hospital and Research Centre, Kanchipuram, Tamilnadu, India

Received: 02 August 2016

Revised: 05 August 2016

Accepted: 08 August 2016

\section{*Correspondence:}

Dr. Sajeetha Kumari R.,

E-mail: sajeethaprabhakar@gmail.com

Copyright: () the author(s), publisher and licensee Medip Academy. This is an open-access article distributed under the terms of the Creative Commons Attribution Non-Commercial License, which permits unrestricted non-commercial use, distribution, and reproduction in any medium, provided the original work is properly cited.

\section{ABSTRACT}

Background: Maternal age is an important determinant of pregnancy outcome and women aged 35 years and above delivering their first child are considered as at risk obstetric patients. The objective of this study was to determine and compare the obstetric outcome in nulliparous women 35 years and above with nulliparous women of age between 20 and 29 years of age and to compare the gestational age, birth weight, Apgar score and neonatal outcome in the two groups.

Methods: It was a retrospective study done in a tertiary care hospital in South India. 192 elderly nulliparous women more than 35 years of age who delivered at this hospital during the study period were taken as study group and nulliparous women aged 20-29 years recorded next serially in the parturient register were taken as control. Selected maternal and perinatal sociodemographic factors and other outcome variables were extracted. The data were entered into a personal computer and analyzed.

Results: Preeclampsia, GDM, fibroid complicating pregnancy, abruption, caesarean section rates (both elective and emergency), low birth weight babies and anomalous babies were significantly higher in elderly nulliparous women than the younger nulliparous controls. There was no significant difference in other maternal and perinatal outcome measures.

Conclusions: The elderly nulliparous women are at increased risk of pregnancy complications. Hence, these patients require careful management in a multidisciplinary tertiary care hospital.

Keywords: Elderly, Nulliparous, Obstetric outcome, Pregnancy complications

\section{INTRODUCTION}

Pregnancy has for generations been portrayed as a wonderful time of anticipation the ultimate reason for being a woman. In current society, women have changed their life patterns such as obtaining higher education, entry into a workforce, and career development. Consequently they often postpone childbearing resulting in an increase in elderly mothers. Being 35 or over does raise certain important issues for woman choosing to wait to start a family. There is a gradual decrease in fertility after the age of 35 so a couple may take longer to conceive, or have to face problems of subfertility.

Traditionally, pregnancies in women of advanced maternal age have been regarded as high risk pregnancies. It is unfortunately true that simply by being older, a woman has had more chances to develop medical disorders such as diabetes, hypertensive disorders or fibroids. In addition the incidence of chromosomal abnormalities, spontaneous abortions, perinatal morbidity and mortality and other obstetric complications are increased. $^{1,2}$ The chance of caesarean section is also 
found to be more in women over 35 years. ${ }^{3}$ Many debates have taken place about whether these women are at greater risk for pregnancy complications because of their age. ${ }^{4}$ Objective of the study was to assess and compare the obstetric outcome in nulliparous women 35 years and above with nulliparous women of age between 20 and 29 years of age and to compare the birth weight, Apgar score and neonatal outcome in the two groups.

\section{METHODS}

This retrospective case control study was carried out in a tertiary care centre in South India, where all elderly nulliparous women who delivered in the age group 35 years and above, during the study period were taken as case and nulliparous women aged 20-29 years recorded next serially in the parturient register were taken as control. Women who delivered before 28 weeks were excluded from the study. Women were seen after delivery either in the labour room or before discharge from the hospital. A detailed history was taken regarding her sociodemographic factors, previous history of abortions, treatment for infertility, antenatal care and presence of medical complications and obstetric complications if any. Her labour process, mode of delivery, intrapartum complications were also recorded. Details of the baby were also noted weight, apgar score, newborn nursery admission if any and the neonatal outcome. Also included in this study were those elderly nulliparous women who had elective caesarean section. The mother was followed up postnatally for any puerperal complications. Nulliparous women in the age group 20-29 years recorded next serially in the parturient register were taken as control and studied in the same manner.

The data collected were entered into a master sheet and statistical tables were constructed. In order to compare the two groups and to get valid inference about the data, statistical constants like mean, standard deviation and percentage were computed. Results were compared using Chi-square test keeping the p-value of $<0.05$ as significant. All statistical calculations were done using computer packages.

\section{RESULTS}

In this study the mean age in the study group was 36.6 and in the control group it was 23.2. Among the women in the age group 35 years and above the history of abortion was present in $28.1 \%$ of the cases when compared to $10.9 \%$ among women in the age group 20 29 years; which was found to be statistically significant with an odds ratio of 3.19 (Table 1). Thus there was a threefold increased incidence of previous abortions noted among the study group compared to the control group. In both the groups $80-90 \%$ was booked cases of the institution, while $10-18 \%$ was booked outside. Thus there was no appreciable difference between the two groups with respect to the booking status. It was seen that in both the study group and control group $65-75 \%$ of the women were from a rural setup and 25-35\% of women came from an urban area. There is not much of a difference between the two groups. Majority of the women were hindus in either group. Muslims were slightly higher in the study group but it was not found statistically significant. This may be due to the early age of marriage among muslims.

Table 1: History of previous abortions.

\begin{tabular}{|lllll|}
\hline & \multicolumn{2}{c}{ Case } & \multicolumn{2}{c|}{ Control } \\
& No & $\%$ & No & $\%$ \\
\hline Present & 54 & 28.12 & 21 & 10.93 \\
\hline Absent & 138 & 71.87 & 171 & 89.06 \\
\hline Total & 192 & & 192 & \\
\hline
\end{tabular}

$* \chi^{2}=18.04 ; \mathrm{p}$ value -0.000 ; significant; Odds ratio- 3.19

$95 \%$ confidence limit $-1.8-5.5$

More women in the study group belonged to high class $(15 \%)$ or middle class $(51 \%)$ when compare to the control group. This was found statistically significant with odds ratio of 1.83.i.e, there is two times more chance for an elderly mother to be from a higher class. While considering the educational status, more women in the study group were better educated (43\%) when compared to the women in the control group (28\%).This was found significant statistically. In the present study, $18 \%$ of the study groups were employed compared to $8 \%$ in the control group. This was found statistically significant with an odds ratio of 2.4 (Table 2).

It was noted that $135(70.3 \%)$ out of the 192 cases included in the study group had antenatal complications. At the same time, in the control group only 90 women $(46.8 \%)$ had such problems. Infact, the risk of antenatal complications were about three times higher in the women of age group 35 years and above. This association was established statistically (Table 3 ). While considering the maternal diseases complicating pregnancy, preeclampsia was a major problem in the study group. $21 \%$ of the women in the study group had preeclampsia where as in the control group it was only $12 \%$.Appling the $\chi 2$ test, this was found significant with an odds ratio of 1.9 .

GDM was present in 34 cases in the study group (18\%) and 7 cases in the control group (4\%). This difference was also statistically significant with an odds ratio of 5.7.The incidence of fibroid complicating pregnancy was significantly higher in the study group compared to the control group (14\% and 1.6\%).Odds ratio was found to be 10.3.Fibroids were 10 times more common among elderly nulliparous women. There were 5 cases of overt diabetes in the study group (3\%) and no case in the control group. Similarly, there were 4 cases of abruption (2\%) in the study group and no case in the control group. Applying $\chi 2$ test both these were found significant. The incidence of preterm labour was $11 \%$ in the study group and $5 \%$ in the control group. This was found significant statistically ( $\mathrm{p}$ value 0.03 ) with an odds ratio of 2.235 . 
Table 2: Sociodemographic characteristics.

\begin{tabular}{|c|c|c|c|c|}
\hline Characteristic & Cases (\%) & Control (\%) & $x^{2}$ & P value \\
\hline \multicolumn{5}{|l|}{ Booking status } \\
\hline Booked & $159(82.81 \%)$ & $171(89.06 \%)$ & 3.1 & 0.07 \\
\hline Booked outside & $31(16.14 \%)$ & $21(10.93 \%)$ & & \\
\hline Unbooked & $2(1.04 \%)$ & 0 & & \\
\hline Total & 192 & 192 & & \\
\hline \multicolumn{5}{|l|}{ Domicile } \\
\hline Rural & $132(68.75 \%)$ & $142(73.95 \%)$ & 1.27 & 0.25 \\
\hline Urban & 60(31.25\%) & $50(26.04 \%)$ & & \\
\hline Total & 192 & 192 & & \\
\hline \multicolumn{5}{|l|}{ Religion } \\
\hline Hindu & $140(72.9 \%)$ & $136(70.83 \%)$ & 0.606 & 0.738 \\
\hline Christian & $31(16.1 \%)$ & $30(15.63 \%)$ & & \\
\hline Muslim & $21(10.9 \%)$ & $26(13.54 \%)$ & & \\
\hline Total & 192 & 192 & & \\
\hline \multicolumn{5}{|c|}{ Socioeconomic status } \\
\hline High & $29(15.1 \%)$ & $21(10.93 \%)$ & 8.4 & 0.004 \\
\hline Middle & $97(50.52 \%)$ & $77(40.1 \%)$ & & \\
\hline Low & $66(34.37 \%)$ & $94(48.95 \%)$ & & \\
\hline Total & 192 & 192 & & \\
\hline \multicolumn{5}{|l|}{ Education } \\
\hline College & $82(43 \%)$ & $54(28 \%)$ & 5.1 & 0.02 \\
\hline School & $110(57 \%)$ & $138(72 \%)$ & & \\
\hline Total & 192 & 192 & & \\
\hline \multicolumn{5}{|l|}{ Occupation } \\
\hline Housewife & $158(82.3 \%)$ & $176(91.6 \%)$ & 7.45 & 0.006 \\
\hline Unskilled & $14(7.3 \%)$ & $5(2.6 \%)$ & & \\
\hline Professional & $3(1.6 \%)$ & $2(1.04 \%)$ & & \\
\hline Skilled & $17(8.9 \%)$ & $9(4.7 \%)$ & & \\
\hline Total & 192 & 192 & & \\
\hline
\end{tabular}

Anemia, IUGR, oligamnios and breech presentation were all found high in the study group though they were not found statistically significant. Spontaneous labour was found high in the control group $(51 \%)$ compared to the study group (34\%). Induced labour was also less in the study group (30\% vs. $43 \%$ ). This may be due to the increased incidence of elective caesarean section among the study group (40.7) when compared to the control group (6.35). It is proved beyond doubt that the incidence of elective caesarean section was remarkably high in the study group. Induction of labour was carried out in 57 $(29.7 \%)$ elderly women as compared to $82(42.7 \%)$ young women. This was found to be statistically significant with an odds ratio of 1.8 . This may be due to increased incidence of elective caesarean section among elderly women (Table 4).

Among the women in the age group 20-29 years, 75\% had vaginal delivery and the remaining had caesarean section, whereas in the study group only $28 \%$ had vaginal delivery and the remaining $72 \%$ underwent caesarean section. This was found statistically significant with an odds ratio 7.7. So caesarean section is almost 8 times more common in the study group.

Both elective as well as emergency caesarean section was more in the study group. In the study group, $50 \%$ were elective procedures and $50 \%$ emergency procedures whereas in the control group only $25 \%$ were elective procedures and $75 \%$ were emergency procedures. The major indications for elective caesarean section was elderly primi having some complications and cephalopelvic disproportion for the elderly group and placenta previa in the control group; whereas that for emergency procedures was failed induction in both the groups (Table 5). In the present study, $79.7 \%$ of the babies in the control group had a weight of $2.5 \mathrm{~kg}$ or more whereas in the study group only $68.2 \%$ had similar weight. In other words, in the study group $32 \%$ had a low birth weight baby compared to only $20 \%$ in the control group. This was found significant statistically. Therefore there is a strong negative correlation between the maternal age and baby weight. There is almost a 2 times increased risk for low birth weight babies among elderly 
nulliparous women. Low apgar score at one minute was noted in $8 \%$ cases of the study group and $4 \%$ in the control group. Similarly apgar score at 5 minutes was less than 7 in $4 \%$ of the study group and $2 \%$ of the control group. Even though clinically low apgar scores are more in the study group, this was not found significant statistically.

Table 3: Pregnancy complications.

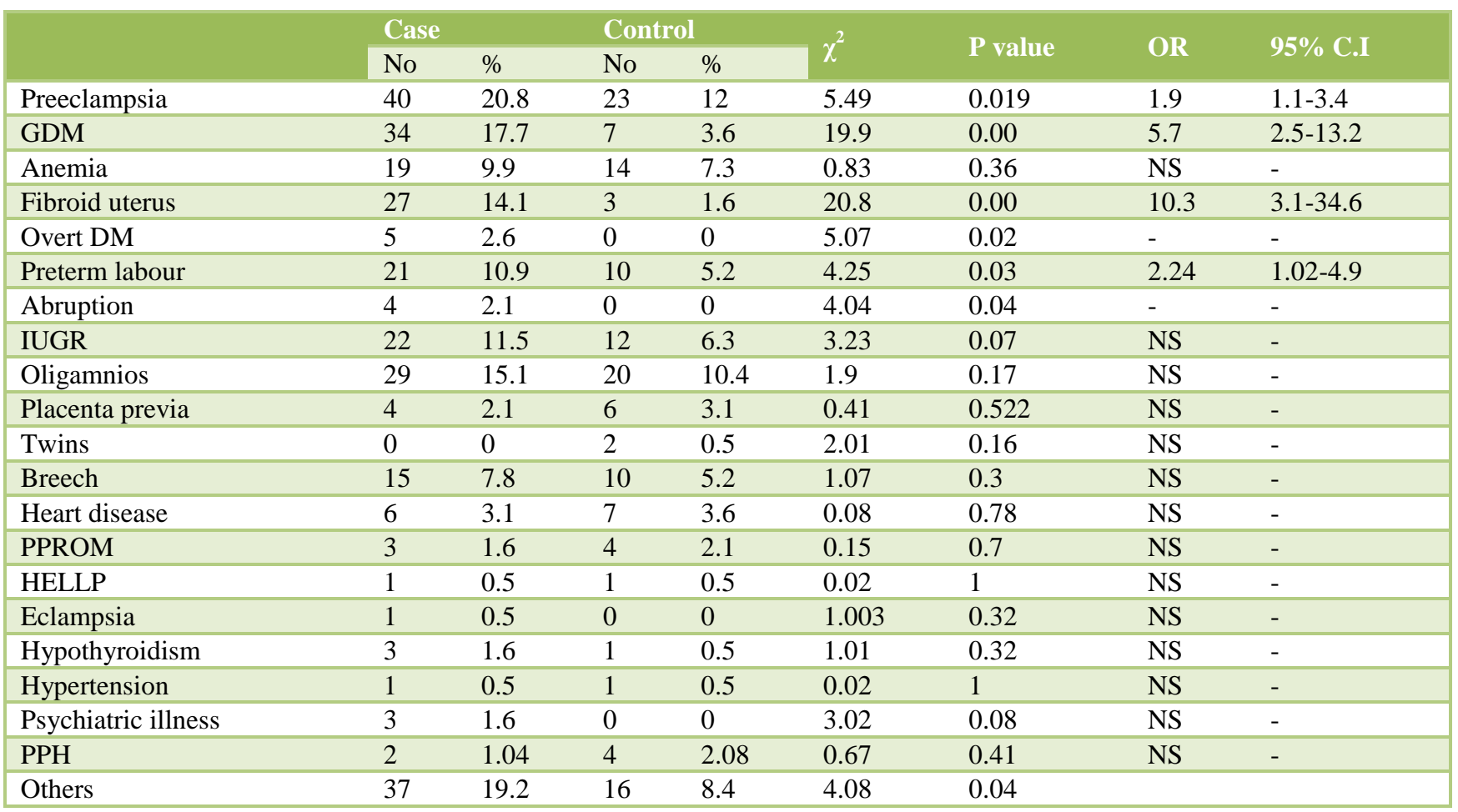

*NS-Not significant; OR-Odds Ratio; CI-Confidence interval

Table 4: Onset of labour.

\begin{tabular}{|lllll|} 
& \multicolumn{2}{c}{ Case } & \multicolumn{2}{c|}{ Control } \\
& No & $\%$ & No & $\%$ \\
\hline Spontaneous & 66 & 34.4 & 98 & 51 \\
\hline Elective LSCS & 69 & 35.9 & 12 & 6.3 \\
\hline Induced & 57 & 29.7 & 82 & 42.7 \\
\hline Total & 192 & & 192 & \\
\hline \hline
\end{tabular}

In the present study, there were 6 babies with anomalies in the study group (3\%) and 1 baby in the control group $(0.5 \%)$. This was found statistically significant.i.e, there is 6 times increased risk for a baby with anomalies in the elderly nulliparous women (Table 7). There were 22 cases of fetal distress in the study group $(11.5 \%)$ whereas there were only 15 cases $(8 \%)$ in the control group. Although this was found to be clinically significant, statistically it was not found significant.

31 babies in the study group were admitted to newborn nursery (16\%) whereas only 19 babies in the control group required admission (10\%). Even though numerically there is a difference, this was not found significant statistically. The most common indication for admission in the newborn nursery was prematurity in both the groups. The second common indication was neonatal jaundice in the study group and sepsis in the control group. In the control group there were 188 live births $(97 \%)$ and in the study group there were 181 live births. Thus, there was almost 2 times increased risk of perinatal mortality in the study group. But this was not found significant statistically (Table 6).

Table 5: Mode of delivery.

\begin{tabular}{|lllll|}
\hline & Case & \multicolumn{3}{c|}{ Control } \\
& No & $\%$ & No & $\%$ \\
\hline Vaginal & 54 & 28.12 & 144 & 75 \\
\hline Full term & 34 & 17.71 & 112 & 58.33 \\
\hline Preterm & 8 & 4.17 & 12 & 6.25 \\
\hline Breech & 2 & 1.04 & 1 & 0.52 \\
\hline Twin & 0 & - & 2 & 1.04 \\
\hline Forceps & 1 & 0.52 & 3 & 1.56 \\
\hline Vacuum & 9 & 4.69 & 14 & 7.29 \\
\hline Caesarean & 138 & 71.88 & 48 & 25 \\
\hline Elective & 69 & 35.94 & 12 & 6.25 \\
\hline Emergency & 69 & 35.94 & 36 & 18.75 \\
\hline Total & 192 & & 192 & \\
\hline
\end{tabular}

$* \chi^{2}=84.45 ; \mathrm{p}$ value-0.000; significant; Odds ratio $7.7 ; 95 \%$ confidence limit $4.87-12.1$

Clinically puerperal complications were more in the study group (12\%) when compared to the control group (5.7\%). Applying the $\chi^{2}$ test, this was not found 
significant. This may be due to the increased operative interventions among these women (Table 8).

Table 6: Birth outcome.

\begin{tabular}{|lllllll|} 
& \multicolumn{2}{l}{ Case } & \multicolumn{2}{l}{ Control } & $\chi^{2}$ & p-value \\
& No & $\%$ & No & $\%$ & & \\
\hline LBW & 61 & 31.77 & 39 & Preterm & 6.844 & 0.009 \\
\hline $\begin{array}{l}\text { Fetal } \\
\text { distress }\end{array}$ & 22 & 11.45 & 15 & 7.81 & 1.46 & 0.22 \\
\hline Preterm & 31 & 16.14 & 19 & 9.89 & 3.31 & 0.06 \\
\hline $\begin{array}{l}\text { Congenital } \\
\text { anomalies }\end{array}$ & 6 & 3.12 & 1 & 0.52 & 3.63 & 0.05 \\
\hline $\begin{array}{l}\text { NICU } \\
\text { admission }\end{array}$ & 31 & 16.14 & 19 & 9.89 & 3.31 & 0.06 \\
\hline IUD/NND & 11 & 5.72 & 6 & 3.09 & 1.59 & 0.20 \\
\hline
\end{tabular}

*Statistically significant at $\mathrm{p}$ value $<0.05$

Table 7: Anomalies in the baby.

\begin{tabular}{|lllll|}
\hline & Case & \multicolumn{2}{c|}{ Control } \\
& No: & $\%$ & No: & $\%$ \\
\hline Present & 6 & 3.12 & 1 & 0.52 \\
\hline CTEV & 3 & & 1 & \\
\hline ASD & 1 & & 0 & \\
\hline ASD+PDA & 1 & & 0 & \\
\hline Cleft palate & 1 & & 0 & \\
\hline Absent & 186 & 96.87 & 191 & 99.47 \\
\hline Total & 192 & & 192 & \\
\hline
\end{tabular}

* $\chi^{2}=3.63 ; \mathrm{p}$ value-0.05; significant; Odds ratio-6.2; $95 \%$ confidence limit $\quad 1.7-51.6$

Table 8: Puerperal complications.

\begin{tabular}{|lllll|}
\hline & \multicolumn{2}{c}{ Case } & \multicolumn{2}{c|}{ Control } \\
\cline { 2 - 5 } & No & $\%$ & No & $\%$ \\
\hline Urinary infection & 12 & 6.3 & 5 & 2.6 \\
\hline Breast engorgement & 5 & 2.6 & 3 & 1.6 \\
\hline Caesarean wound infection & 5 & 2.6 & 2 & 1 \\
\hline $\begin{array}{l}\text { Episiotomy wound } \\
\text { infection }\end{array}$ & 0 & - & 1 & 0.5 \\
\hline DVT & 1 & 0.5 & 0 & 0 \\
\hline
\end{tabular}

\section{DISCUSSION}

In the present study the mean age in the study group was 36.6 and in the control group it was 23.2.

$28 \%$ of the study group gave history of previous abortion whereas it was only $10.9 \%$ in the control group. There was a threefold increased risk for miscarriages in elderly nulliparous women. This finding agrees with the study by Knudsen et al who reported that the incidence of miscarriage is $20 \%$ in women aged $35-39$ years and exceeds $40 \%$ in women over 42 years of age. ${ }^{1}$ Also, Clifford et al stated that more than $50 \%$ of women over 40 years lost the next pregnancy irrespective of the number of previous losses. ${ }^{2}$
When $65 \%$ of the study group was from high class and middle class families, in the control group it was found to be $51 \%$, which was statistically significant. Also considering the educational status, $48 \%$ of the study group had college education whereas in the control group only $23 \%$ had college education. This finding is similar to the finding reported by Bell et al. ${ }^{3}$

In the present study more women were employed in the study group (18\%) compared with the control group $(8 \%)$. This agrees with the findings of Ziadeh et al, Mehreen Mehdi et al and Suwarnath et al who showed that professionals were more among the elderly nulliparous women. ${ }^{4-6}$

Regarding the booking status, booked outside cases were more in the study group (16\%), but this was not found to be of significance. About the domicile, the two groups were almost comparable. In the present study, the two groups were similar with respect to the religion. Muslims were found slightly less in the study group. This was not statistically significant, but it may be due to the fact that Muslims have an early marriage when compared with others.

In the study group while $70 \%$ had antenatal complications, it was found to be $47 \%$ in the control group. This shows that the risk of antenatal complications were about three times higher in the women of the age group 35 years and above. This is in accordance with other studies showing a higher incidence of antenatal complications in elderly women. When $21 \%$ in the study group had preeclampsia, it was present in only $12 \%$ of the control group. This was found statistically significant with an odds ratio of 1.9. This finding agrees with the study of Joseph et al and Oboro et al who demonstrated that pregnancy induced hypertension was more in elderly nulliparous patients. ${ }^{7,8}$ Studies by Al Turki et al and Ziadeh et al also showed a higher incidence of preeclampsia among elderly nulliparous women. ${ }^{9,4}$ But, Nelson et al showed that the incidence of proteinuric hypertension was little affected, whereas the incidence of hypertension without proteinuria rose after the age of 30 years. ${ }^{10}$

In the study group GDM was identified in 34 cases (18\%) whereas there were only 7 cases $(4 \%)$ in the control group which was statistically significant i.e. there was more than fivefold increase. These findings agree with those of Suchita et al, Gharoro et al and Babrowaski et al who showed an increased incidence of diabetes mellitus in elderly nulliparous women. ${ }^{11-13}$ There were 5 cases of overt diabetes in the study group $(2.6 \%)$, while there was no case in control group. This is significant statistically.

Numerically, anemia was found more among elderly nulliparous women. This may be due to the increased incidence of fibroid in this age group. Studies by Suchita et al and Gharoro et al also reported an increased incidence of anemia in elderly nulliparous women. ${ }^{11,12}$ 
The incidence of fibroid complicating pregnancy was 10 times higher in the study group compared with the control group (14\% vs $2 \%$ ). This agrees with the findings of Gharoro et al who found that the incidence of fibroid was $15 \%$ in nulliparous women above the age of 35 years. ${ }^{12}$ The incidence of placenta previa was found to be less in the study group (2\%) compared to the control group (3\%).

The incidence of abruption was found significantly higher in the study group-4 cases $(2 \%)$. There was no case in the control group. This is in accordance with the study of Ananth et al, who showed an elevated risk of abruption and bleeding in women over 35 years of age. ${ }^{14}$

Intrauterine growth restriction and oligamnios were identified more in the study group (12\% and $15 \%)$ when compared with the control group (6\% and 10\%) but was not found statistically significant. Preterm labour was fond to be more in the study group (12\%) compared to the control group (5\%) which is statistically significant. There is more than two fold increase in the incidence of preterm labour among elderly group. This is in accordance with previous studies by Mehdi et al, Ziadeh et al and Cnattinguis. $4,5,15$

There were 2 cases of multiple pregnancies in the control group whereas no case was identified in the study group. This does not agree with the study of Ziadeh et al who showed that multiple gestations are more common in elderly primigravida. ${ }^{4}$ There were 15 cases of breech presentation in the study group $(8 \%)$ and 10 cases in the control group (5\%). Though statistically this is not significant, clinically there is a difference. This is in accordance with the findings of Jahan MK et al that showed increased chance for malpresentations in elderly primigravida. $^{16}$

Heart disease was found to be slightly less in the study group (3.1\% vs $3.6 \%)$. This does not agree with Mehdi et al who demonstrated that the prevalence of heart disease was more in elderly nulliparous women. ${ }^{5}$ Michael Prysak et al showed that the incidence of hypertension preceeding pregnancy was $2.7 \%$ in elderly nulliparous women. But in the present study there was only 1 case of hypertension complicating pregnancy. ${ }^{17}$

It was seen that in the present study the incidence of spontaneous labour fell from $51 \%$ in the control group to $34 \%$ in the study group. This is almost similar to the findings of Allahabadia et al who showed that the incidence of spontaneous labour was less among elderly nulliparous women. ${ }^{18}$

The incidence of induction of labour was $29.7 \%$ in the study group and $42.7 \%$ in the control group. This does not agree with the studies by Nagarwal $\mathrm{K}$ et al where the induction of labour was found to be 2.7 times more in the elderly women compared to younger women. ${ }^{19}$
The caesarean section rate was found to be higher in the study group (72\%) when compared to the control group (25\%). Previous studies by Naqvi MM et al, Smit S et al and Adashek et al also showed a higher incidence of caesarean section in elderly nulliparous women. ${ }^{20-22}$

There were 69 cases of elective caesarean section in the study group (36\%) compared to 12 cases in the control group $(6 \%)$. The major indications for elective caesarean section was elderly primi having some complications and cephalopelvic disproportion for the elderly group and placenta previa for the control group; whereas that for emergency procedures was failed induction in both the groups.

Regarding operative vaginal delivery, the incidence was found less in the study group (5\% vs $9 \%$ ). This was not found statistically significant. This finding differed from the study of Nirmala et al which showed that the incidence of assisted vaginal deliveries in the elderly group were more than that in the younger age group. ${ }^{23}$ The incidence of postpartum hemorrhage also was found higher in the control group (1\% in the study group and $2 \%$ in the control group). This may be because, elderly nulliparous women are kept only for a short trial of labour and have a less chance for prolonged labour which is an important cause leading to postpartum hemorrhage. This did not agree with the study of Tsu VD who showed that increased maternal age and prolonged labour predisposed to postpartum hemorrhage. ${ }^{24}$

There were 22 cases of fetal distress in the study group (11\%) and 15 cases in the control group (7.8\%). Meconium stained liquor was found slightly less in the study group (5\% vs $6 \%$ ) whereas fetal heart rate changes were more in the study group ( $7 \%$ vs $2 \%$ ). This may be because more of the elderly women have an elective ceasarean section and also the duration of labour is much less in the elderly group. This finding disagrees with Prysak $\mathrm{M}$ et al who showed that meconium stained liquor was more in the elderly women. ${ }^{17}$

In the present study, $32 \%$ of the study group had low birth weight babies compared to only $20 \%$ in the control group. This is in accordance with the findings of Ziadeh et al and Al Turki et al who found that the incidence of low birth weight babies is more among elderly nulliparous women. ${ }^{4,9}$

An apgar score of less than 7 at 5 minutes were seen in 8 cases of the study group (4\%) and 3 cases of the control group (1.5\%). Al Turki et al found that the elderly group had a significant reduction in Apgar scores. ${ }^{9}$

There were 6 anomalous babies in the study group (3\%) and 1 such baby in the control group $(0.5 \%)$. So there is a 6 fold increased incidence of anomalous babies among elderly nulliparous women. This finding is similar to the study by Mehdi et al where $5 \%$ of the babies had fetal malformations compared to $1 \%$ in the younger age 
group. ${ }^{5}$ Lynn Simpson also stated that after 35 years, the risk of chromosomal abnormalities was increased. ${ }^{25}$ If 35 , at the time of delivery, the risk of a chromosomal abnormality in British Columbia was 1 in 190 and by age 40, the risk was 1 in 70 .

In the present study, it was found that more babies from the study group required admission to newborn nursery (16\% vs 10\%).The major reasons for admission of babies to newborn nursery, in the study group were prematurity (48\%) and neonatal jaundice (19\%) whereas in the control group, it was prematurity $(26 \%)$ and sepsis $(21 \%)$. There were 11 cases of perinatal mortality in the study group (5.7\%) and 6 cases in the control group (3\%). Astolfi et al and Ling et al demonstrated an increased incidence of perinatal morbidity in the babies of elderly nulliparous women while this was not demonstrated by Ojule et al. ${ }^{26-28}$

There was no case of maternal mortality in both the groups. In conclusion, childbearing in elderly nulliparous women does have higher rates of complications like preeclampsia, diabetes, abruption, fibroids etc. Also, these women are liable to have more deliveries by caesarean section than by other methods, in spite of lower gestational age and low birth weight. Timely and accurate diagnosis of complications and their treatment leads to favorable outcome. This study suggests that the women in the age group of 35 years and above should be informed of their pregnancy expectations and outcome. They should have intensive antenatal monitoring and help from other specialities should be sought for if required. Genetic testing should be offered and an anomaly scan must be performed because of the high risk of congenital malformations, so that timely intervention could be done with less physical and emotional scarring to the mother. Improved obstetrical care has made advanced maternal age compatible with successful pregnancy for the great majority of such women.

\section{ACKNOWLEDGEMENT}

The authors would like to acknowledge helping rendered by Dr. Revathy and Dr. Solai, of Obstetrics and Gynecology department in the writing process and also the subjects who readily agreed to participate in this study.

\section{Funding: No funding sources}

Conflict of interest: None declared

Ethical approval: The study was approved by the Institutional Ethics Committee

\section{REFERENCES}

1. Knudsen UB, Haansen V, Juul S, Secher NJ. Prognosis of a new pregnancy following previous spontaneous abortions. European J Obstet Gynec Repro Biol. 1991;39:31-6.
2. Clifford K, Rai R, Regan L. Future pregnancy outcome in unexplained recurrent miscarriage. Hum Reprod. 1997;12:387-9.

3. Bell JS, Campbell DM, Graham WJ, Penney GC, Ryan M, Hall MH. Do obstetric complications explain high caesarean section rates among women over 30? A retrospective analysis. British Med J. 2001;322(7291):894-5.

4. Ziadeh S. Maternal and perinatal outcome in nulliparous women aged 35 and older. Gynecol Obstet Invest. 2002;54:6-10.

5. Mehdi M, Naseem A. Obstetrical risks on the older primigravidas. Journal of the College of Physicians and Surgeons Pakistan. 2004;14:5.

6. Suwarnath C, Pinijaroen S. Pregnancy outcome in elderly primigravidas in Songlanagarind Hospital. Songkla Med J. 1998;16(2):57-63.

7. Joseph KS, Allen AC, Dodds L, Turner LA, Scott H, Liston R. The Perinatal Effects of Delayed Childbearing. Obstet Gynecol. 2005;105:1410-8.

8. Oboro VO, Dare FO. Pregnancy outcome in nulliparous women aged 35 or older. West Afr J Med. 2006;25(1):65-8.

9. Al THA, Abu HAT, Alsibai MH. The outcome of pregnancy in elderly primigravidas. Saudi Med J. 2003;2(11):1230-3.

10. Nelson. Risk of hypertension as age advances. Br J Obstet Gynecol. 1995;23:169.

11. Pandit S, Kale D. Obstetris outcome in elderly primigravida... How did they fare? Bombay Hospital Journal. 2011;53(4):715-20.

12. Gharoro EP, Igbafe AA. Maternal age at first birth and obstetric outcome. Nigerian J Clinical Practice.2002;5(1):20-4.

13. Babrowski R, Bottoms SF. Under appreciated kisks of elderly nullipara. Am J Obstet Gynecol. 1995;172(6):1764.

14. Ananth CV, Savitz DA, Watson A, Luther R. Influence of hypertensive disorders and cigarette smoking on placental abruption and uterine bleeding during pregnancy. $\mathrm{Br} \mathrm{J}$ Obstet Gynecol. 1997; 104:572.

15. Cnattinguis S, Forman MR, Berendes HW, Isotalo L. Delayed child bearing and risk of adverse perinatal outcome. J Am Med Asso. 1992;268:886.

16. Jahan MK, Shafiquzzaman M, Nahar K, Rahman M, Sultana N, Rahman MM, et al. Outcome of pregnancy in women 35 years of age and above. Mymensingh Med J. 2009;18(1):7-12.

17. Prysak M, Lorenz RP, Kisly A. Pregnancy outcome in nulliparous women 35 years and older. Am J Obstet Gynecol. 1994;85:65.

18. Allahabadia G, Vaidya P, Ambiya VR. Ind Medic Assoc. 1994;92(5):144.

19. Nagarwal K, Chandrakanta, Gaur K, Manohar RK. Pregnancy outcome comparison in elderly and nonelderly primigravida. International Multispeciality Journal Health. 2015;1(1):24-30. 
20. Naqvi MM, Naseem A. Obstetrical risks in the older primigravida. J Coll Physicians Surg Pak. 2004;14(5):278-81.

21. Smit Y, Scherjon SA, Knuist M, Treffers PE. Obstetric outcome of elderly low risk nulliparae. Int J Gynecol Obstet. 1998;63(1):7-14.

22. Adashek JA, Peaceman AM, Lopez J, Minogue JP, Socol ML. Factors contributing to the increased caesarean birth rate in older parturient women. Am J Obstet Gynecol. 1993;169:963.

23. Ramachandran N, Sethuraman D, Nachimuthu V, Natarajan T. Obstetric and perinatal outcome of elderly mothers aged 35 years and above: a comparative study. Int J Res Med Sci. 2015;3(1):214-9.

24. Tsu VD. Postpartum haemorrhage in Zimbabwe: A risk factor analysis. $\mathrm{Br} \mathrm{J}$ Obstet Gynecol. 1993;100:327-33
25. Simpson L. Fertility after 35, Fall 2004 issue of Urban Baby and Toddler Magazine. 2004.

26. Astolfi D, Pasquale A, Zono LA. Late child bearing and its impact on adverse pregnancy outcome: stillbirth, preterm delivery and low birth weight. Rev Epidemiol sante Publique.2005;53:97-105.

27. Ling H, Sauve R, Nicholas B, Fergusson D, Carl VW. Maternal age and risk of stillbirth - a systematic review. Canadian Med Asso J.2008;178(2):165-72.

28. Ojule JD, Ibe VC, Fiebai PO. Pregnancy outcome in elderly primigravidae. Ann Afr Med. 2011;10:204-8.

Cite this article as: Raveendran S, Mohanapu S, Murugaiah Y. Obstetric outcome in elderly nulliparous women: a comparative study. Int $\mathbf{J}$ Reprod Contracept Obstet Gynecol 2016;5:2921-8. 